\title{
TERAPI AKTIFITAS KELOMPOK STIMULASI SENSORI DALAM UPAYA PENCEGAHAN GANGGUAN PSIKOSOSIAL LANJUT USIA
}

\section{[SENSORY STIMULATION GROUP ACTIVITY THERAPY IN EFFORTS TO PREVENT AGE PSYCHOSOCIAL DISORDERS]}

\author{
Yanni Karundeng, Maykel A. Kiling, Yourisna Pasambo, \\ Janbonsel Bobaya, Marjes N. Tumurang, Isworo \\ Jurusan Keperawatan Poltekkes Kemenkes Manado \\ e-mail : yourisna84@gmail.com \\ DOI : 10.47718/jpd.v8i01.1167
}

\section{ABSTRAK}

Latar Belakang: Proses penuaan secara alamiah akan menimbulkan masalah fisik, mental, sosial, ekonomi dan psikologis. Gangguan psikososial yang dialami lanjut usia seperti ketergantungan pada orang lain, mengisolasi diri atau menarik diri dari kegiatan kemasyarakatan. Klien cenderung tidak mau berkomunikasi verbal dan akan berdampak pada emosi dan perasaannya. Pemberian terapi aktivitas kelompok stimulasi sensoris adalah agar klien mampu mengekpresikan perasaannya. Jadi, dengan mengekspresikan perasaan melalui terapi aktivitas kelompok stimulasi sensoris dapat mengurangi gangguan psikososial lanjut usia. Tujuan: mengetahui pengaruh terapi aktivitas kelompok stimulasi sensoris terhadap gangguan psikososial lanjut usia. Metode: quasi eksperimental design, non equivalent control group design dengan teknik pengambilan sampel yaitu purposive sampling terhadap 40 responden yang dibagi dalam 20 lansia untuk kelompok eksperimen dan 20 lansia untuk kelompok kontrol. Teknik pengumpulan data melalui observasi dan wawancara. Hasil: terdapat perbedaan nilai $p$ dari kelompok eksperimen dan kelompok kontrol, dimana pada kelompok eksperimen nilai $\mathrm{p}=$ 0,000 lebih kecil dari 0,05 dan pada kelompok kontrol $p=0,317$. hal ini menunjukkan bahwa ada pengaruh terapi aktivitas kelompok stimulasi sensoris terhadap gangguan pikososial pada kelompok intervensi. Sedangkan pada kelompok kontrol yang tidak diberikan terapi aktivitas kelompok stimulasi sensoris tidak berpeluang mengalami penurunan gangguan psikologis. Kesimpulan: ada pengaruh yang bermakna terhadap gangguan psikososial lansia 
maka panti werda seyogyanya menyusun kegiatan tentang terapi aktivitas kelompok dilaksanakan secara berkesinambungan. Pendidikan keperawatan perlu membangun kerjasama dengan layanan pelayanan keperawatan dalam mengembangkan praktek keperawatan berbasis terapi komplementer terapi aktifitas kelompok.

Kata Kunci: Terapi Aktifitas Kelompok; Gangguan Psikosial; Lanjut Usia.

\section{ABSTRACT}

Introduction: The aging process will naturally cause physical, mental, social, economic and psychological problems. Psychosocial disorders experienced by the elderly, such as dependence on other people, isolating themselves or withdrawing from social activities. Clients tend not to want to communicate verbally and will have an impact on their emotions and feelings. Providing sensory stimulation group activity therapy is so that clients are able to express their feelings. So, by expressing feelings through sensory stimulation group activity therapy can reduce the psychosocial disorders of the elderly. Aim: to determine the effect of sensory stimulation group activity therapy on elderly psychosocial disorders. Method: quasi experimental design, non-equivalent control group design with the sampling technique, namely purposive sampling of 40 respondents divided into 20 elderly for the experimental group and 20 elderly for the control group. Data collection techniques through observation and interviews. Results: there is a difference in the $p$ value of the experimental group and the control group, where in the experimental group the $p$ value $=$ 0.000 is smaller than 0.05 and in the control group $p=0.317$. This shows that there is an effect of sensory stimulation group activity therapy on picosocial disorders in the intervention group. Meanwhile, the control group who was not given activity therapy in the sensory stimulation group had no chance of experiencing a decrease in psychological disorders. Conclution: there is a significant effect on the psychosocial disorders of the elderly, therefore the werda nursing home should arrange activities on group activity therapy to then be carried out on an ongoing basis. Nursing education needs to build collaboration with nursing service services in developing nursing practice based on complementary 
therapy group activity therapy.

Key words: Group Activity Therapy; Psychosocial Disorders; Elderly

\section{PENDAHULUAN}

Seiring dengan keberhasilan pemerintah dalam pembangunan nasional, telah mewujudkan hasil yang positif diberbagai bidang, yaitu adanya kemajuan ekonomi, perbaikan lingkungan hidup, kemajuan ilmu pengetahuan dan teknologi, terutama di bidang medis atau ilmu kedokteran sehingga dapat meningkatkan kualitas kesehatan penduduk yang berusia lanjut meningkat dan bertambah cenderung lebih cepat. (Nugroho W, 2008)

Berdasarkan laporan data demografi penduduk Internasional yang dikeluarkan oleh Bureau af the Census USA bahwa di Indonesia pada kurun waktu tahun 1990 - 2025 akan terjadi kenaikan jumlah lanjut usia sebesar $414 \%$, suatu angka kenaikan tertinggi di seluruh dunia. Adanya peningkatan jumlah lansia, masalah kesehatan yang dihadapi bangsa Indonesia menjadi semakin kompleks, terutama yang berkaitan dengan gejala penuaan. (Sihurian P, 2007)

Di Indonesia berdasarkan data sensus penduduk menunjukan jumlah lansia tahun 2010 sebanyak 18,1 juta jiwa ( 7,6 persen dari total populasi), tahun 2014 meningkat menjadi 20,24 juta jiwa ( 8,03 persen populasi), dan diperkirakan akan mencapai 36 juta jiwa pada 2025. Di Propinsi Sulawesi Utara lanjut usia berjumlah 191.853 jiwa yang terdiri dari lakilaki 88.180 jiwa dan perempuan 103.673 jiwa.(Http://www.Data Statistik Indonesia 2017.com/)

Proses menua di dalam perjalanan hidup manusia merupakan suatu hal wajar yang akan di alami semua orang yang di karuniai umur panjang, hanya lambat cepatnya proses tersebut bergantung pada masing-masing individu yang bersangkutan. Secara individu, pada usia di atas 55 tahun 
terjadi proses penuaan secara alamiah. Hal ini akan menimbulkan masalah fisik, mental, sosial, ekonomi dan psikologis. (Nugroho W, 2008)

Lansia banyak mengalami kemunduran dari segi fisik, psikologi, social, ekonomi, kesehatan. Oleh karena itu diperlukan perhatian dan penanganan yang lebih baik, seperti yang tercantum dalam Undangundang Nomor 13 tagun 1998 tentang kesejahtraan lanjut usia.

Hal-hal yang dapat menimbulkan gangguan keseimbangan sehingga membawa lansia kearah kemerosotan yang progresif terutama aspek psikologis dan sosial, misalnya bingung, panik, depresi, apatis, kematian pasangan hidup, berurusan dengan pihak hukum atau trauma psikis dan tidak mau bergaul. Keadaan itu berpotensi menimbulkan masalah kesehatan secara umum maupun kesehatan jiwa secara khusus pada lansia. Di antaranya adalah secara psikososial yaitu ketergantungan pada orang lain, mengisolasi diri atau menarik diri dari kegiatan kemasyarakatan. Hal lain yang dapat terjadi adalah timbulnya gangguan keseimbangan (Homeostasis) sehingga membawa lansia kearah kerusakan/ kemerosotan (Deteriorisasi) yang progresif terutama aspek psikologis yang mendadak, misalnya bingung, panic, depresif, apatis, dan sebagainya. (Sihurian P, 2007)

Melihat masalah - masalah yang telah dikemukakan sudah sewajarnya bahwa kelompok lansia perlu mendapat pembinaan untuk meningkatkan derajat kesehatan dan mutu kehidupan untuk mencapai masa tua yang bahagia dan berguna bagi kehidupan keluarga dan masyarakat sesuai dengan eksistensinya dalam strata kemasyarakatan. Salah satu upaya untuk meningkatkan derajat kesehatan dan mutu kesehatan lansia adalah dengan menerapkan terapi aktivitas kelompok. Terapi aktifitas Kelompok (TAK) lansia merupakan salah satu cara agar lansia berpartisipasi aktif dalam kegiatan yang dapat mempengaruhi 
psikososialnya.(Juniati S, 2011)

Terapi aktivitas kelompok merupakan salah satu terapi modalitas yang dilakukan perawat terhadap sekelompok klien yang mempunyai masalah keperawatan yang sama. Aktivitas digunakan sebagai terapi, dan kelompok digunakan sebagai target asuhan. Di dalam kelompok terjadi dinamika interaksi yang saling bergantung, saling membutuhkan, dan menjadi laboratorium tempat klien berlatih perilaku baru yang adaptif untuk memperbaiki perilaku lama yang maladaptif. (Keliat B A, 2015)

Dengan berbagai permasalahan ini penulis memfokuskan penelitian di Panti Agape Tondano dan Panti Debora Tondano. Berdasarkan survey awal yang diperoleh pada bulan Desember 2017, terdapat 24 orang jumlah lansia di Panti Agape dan 35 orang di Panti Debora Tondano. Berdasarkan observasi dan wawancara langsung yang dilakukan peneliti pada survey awal ternyata terdapat 6 lanjut usia yang sering marahmarah, lansia yang mengalami ketergantungan, lansia yang mengalami depresi, lansia yang merasa sedih karena kehilangan keluarga terdekat. Lansia tersebut ternyata kurang mendapat kunjungan dari keluarga, baru saja di tinggal oleh sanak keluarga terdekat, lansia yang ekonominya rendah, lansia yang masih lajang, lansia yang hidup sendiri, lansia yang baru saja berada dipanti dan sebagainya. Terapi aktivitas kelompok : Stimulasi sensoris baik dilakukan pada lanjut usia untuk mengatasi masalah-masalah pada lanjut usia.

\section{METODE PENELITIAN}

Penelitian ini merupakan penelitian kuantitatif dengan

desain quasi eksperiment design with pre - post test control group. Bentuk rancangan ini adalah sebagai berikut (Notoatmodjo, 2012). Teknik pengambilan sampel dalam penelitian ini adalah dengan cara porpusive sampling. Sampel dalam penelitian ini sebanyak 40 
HASIL DAN PEMBAHASAN

responden yang terdiri dari 20 responden untuk kelompok intervensi dan 20 responden untuk kelompok control. Penelitian dilaksanakan di Panti Werda Agape dan Debora Tondano. Pengumpulan data ini dilakukan dengan menggunakan teknik observasi dan wawancara terbimbing. Lembar observasi gangguan psikososial lanjut usia. Teknik pengolahan data denga analisis univariat untuk mendeskripsikan setiap variable yang diteliti. Analisis bivariate dilakukan untuk mengetahui bentuk hubungan kedua variable. Uji yang digunakan "Uji ranking" bertanda Wilcoxon dengan statistik $Z$, dimana kaidahnya : Harga $z$ hitung lebih besar dari tabel maka Ho ditolak dan Ha diterima apabila $p<0.05$

Penyajian data diawali dengan hasil analisis univariat
terhadap karakteristik responden yang meliputi : umur, jenis kelamin.

Tabel 1 Distribusi Responden Berdasarkan Data Demografi Responden di Panti Agape dan Debora Tondano

\begin{tabular}{llccccc}
\hline Variabel & \multicolumn{2}{c}{$\begin{array}{c}\text { Kelompok } \\
\text { Intervensi }\end{array}$} & \multicolumn{2}{c}{$\begin{array}{c}\text { Kelompok } \\
\text { Kontrol }\end{array}$} & Total & $\%$ \\
& $\mathrm{f}$ & $\%$ & $\mathrm{f}$ & $\%$ & & \\
\hline Umur (tahun) : & & & & & & \\
$60-74$ & 11 & 55 & 14 & 70 & 25 & 62,5 \\
$75-90$ & 9 & 45 & 6 & 30 & 15 & 37,5 \\
Jenis Kelamin: & & & & & & \\
Laki-laki & 4 & 20 & 5 & 25 & 9 & 22,5 \\
Perempuan & 16 & 80 & 15 & 75 & 31 & 77,5 \\
\hline
\end{tabular}

Berdasarkan tabel satu, sebagian besar responden baik kelompok intervensi maupun kelompok kontrol umur berada pada rentang umur 60 - 74 tahun. Sementara untuk jenis kelamin, 
sebagian besar responden berjenis kelamin perempuan, baik kelompok kontrol maupun kelompok intervensi.

Tabel 2 : Hasil Analisis pengaruh terapi aktivitas kelompok stimulasi sensoris terhadap gangguan psikososial lanjut usia kelompok intervensi

\begin{tabular}{lccccr}
\hline \multicolumn{1}{c}{ Hasil } & Tanda Jenjang & $\mathrm{n}$ & $\%$ & $\mathrm{z}$ & $p$-Value \\
\hline Posttest-pretest & Ranking Negatif & 0 & 0 & & \\
Gangguan Psikososial & Ranking Positif & 19 & 95 & -3.903 & 0,000 \\
Lansia Kelompok & Tetap & 1 & 5 & & \\
Intervensi & Total & 20 & 100 & & \\
\hline
\end{tabular}

Pada tabel dua menunjukan bahwa 20 orang responden, yang menunjukkan nilai posttest < pretest (ranking negatif) berjumlah 0 responden atau $0 \%$, dan nilai posttest $>$ pretest (ranking positif) berjumlah 19 responden yaitu 95\% dan nilai posttest $=$ pretest berjumlah 1 responden atau $5 \%$. Dari hasil uji ranking bertanda wilcoxon dengan menggunakan statistik $\mathrm{z}$ didapatkan nilai z -3.903 dengan taraf kesalahan 0,05 dan tingkat kepercayaan $95 \%$ maka nilai $p=0,000<0,05$.

Tabel 3 Hasil Analisis pengaruh terapi aktivitas kelompok stimulasi sensoris terhadap gangguan psikososial lanjut usia kelompok kontrol

\begin{tabular}{lccccc}
\hline \multicolumn{1}{c}{ Hasil } & Tanda Jenjang & $\mathrm{n}$ & $\%$ & $\mathrm{Z}$ & $p$-Value \\
\hline Postest-pretest & Ranking Negatif & 1 & 5 & & \\
Gangguan & Ranking Positif & 3 & 15 & 1.000 & 0,317 \\
psikososial lanjut & Tetap & 16 & 80 & & \\
$\begin{array}{l}\text { usia kelompok } \\
\text { control }\end{array}$ & Total & 20 & 100 & & \\
\hline
\end{tabular}

Pada tabel tiga menunjukan bahwa 20 orang responden, yang menunjukkan nilai posttest < pretest ( ranking negatif) berjumlah 1 orang atau $5 \%$, dan nilai posttest > pretest (ranking 
positif) berjumlah 3 orang yaitu $15 \%$ dan nilai posttest $=$ pretest berjumlah 16 responden atau 80 \%. Dari hasil uji ranking bertanda wilcoxon dengan menggunakan statistik z didapatkan nilai z $-1,000$ dengan taraf kesalahan 0,05 dan tingkat kepercayaan 95 \% maka nilai $p=0,317>0,05$.

Adapun untuk mengetahui hasil analisa pengaruh terapi aktivitas kelompok stimulasi sensori terhadap gangguan psikososial lanjut usia dilakukan uji statistik $Z$ dengan kemaknaan $p=0,05$. Hasil uji ranking bertanda wilcoxon dengan menggunakan statistik z didapatkan nilai z untuk kelompok intervensi -3,903 dengan taraf kesalahan 0,05 dan tingkat kepercayaan $95 \%$ maka nilai $p=$ $0,000<0,05$. Sedangkan pada kelompok kontrol nilai z adalah 1,000 dengan taraf kesalahan 0,05 dan tingkat kepercayaan $95 \%$ maka nilai $p=0,317>0,05$. Dengan ,membandingkan nilai kapasitas uji dua pihak ( 2 tailed) terlihat bahwa pada kelompok intervensi nilai $\mathrm{p}$ $=0,000$ dan kelompok kontrol $p=0,317$ berarti nilai $p$ untuk kelompok intervensi < nilai $\mathrm{p}$ kelompok kontrol. Sehingga perbandingan nilai ini dapat dikatakan peluang kelompok eksperimen menolak Ho > kelompok kontrol. Hal ini menunjukkan bahwa kelompok intervensi yang diberikan perlakuan yaitu Terapi Aktivitas Kelompok Simulasi Sensori memberi hasil yang bermakna. Jadi ada pengaruh pengaruh terapi aktivitas kelompok stimulasi sensoris terhadap gangguan psikososial lanjut usia.

Tabel 1 menunjukkan bahwa terdapat 2 kategori umur yaitu lanjut usia (Elderly) berumur antara 60 - 74 tahun dan lanjut usia 
tua (Old) berumur antara 75 - 90 tahun menurut WHO (Nugroho, 2012). Menurut Nugroho (2012) bahwa dengan bertambahnya usia, seseorang secara berangsur-angsur mulai melepaskan diri dari kehidupan sosialnya atau menarik diri dari pergaulan sekitarnya sehingga mengakibatkan interaksi sosial lanjut usia menurun. Lumban Tobing (2001) juga mengemukakan bahwa semakin tuanya umur seseorang akan cenderung mengarah pada suatu kondisi/ keadaan yang dapat menyebabkan gangguan psikososial.

Dari hasil penelitian menunjukkan kelompok eksperimen berdasarkan jenis kelamin perempuan Menurut Stanley M (2002), lebih banyak perempuan yang berusia di atas 65 tahun dibanding pria karena umur wanita lebih panjang dari pria. Salah satu factor yang mempengaruhi gangguan psikososial adalah jenis kelamin. Pola komunikasi perempuan berbeda dengan laki-laki. Perempuan lebih cenderung memikirkan masalahnya dan kurang mengkomunikasikan dengan orang lain sehingga emosi labil yang sering mengakibatkan gangguan psikososial. Depresi merupakan kelainan alam perasaan yang bias menyebabkan hilangnya minat dan kesenangan dalam beraktifitas.

Dalam penelitian ini peneliti memberikan terapi aktivitas kelompok stimulasi sensoris sebanyak 3 kali, masing-masing terapi terbagi atas 3 sesi yang diberikan selama 1 hari. jarak pemberian terapi selama 3 hari. Pada hari ke-9 setelah pemberian terapi, peneliti melakukan observasi gangguan psikososial pasca intervensi (postest). 
Penurunan gangguan psikososial lanjut usia sesungguhnya tidak lepas dari pemberian terapi aktifitas kelompok simulasi sensori. Sehingga gangguan psikososial menunjukkan adanya perubahan setelah diberikan terapi aktifitas kelompok simulasi sensori. Hal ini sudah dibuktikan peneliti bahwa dengan pendekatan keperawatan, pemberian terapi aktifitas kelompok stimulasi sensori telah membawahkan hasil.

Penelitian ini yang telah dilakukan di di Panti Agape dan Debora Tondano dengan hasil uji statistik Wilcoxon Signed Ranks Test pada responden terdapat pengaruh yang signifikan dimana nilai $p$-value $=0,000(\alpha=0,05)$, yang berarti $\mathrm{HO}$ ditolak. Hasil yang diperoleh dari penelitian ini menunjukkan adanya penurunan ganggauan psikososial sebelum dan sesudah diberikan terapi aktifitas kelompok simulasi sensori.

Penelitian yang dilakukan Nurafifah tentang "terapi aktifitas kelompok simulasi sensori terhadap tingkat depresi lansia)" di dapatkan hasil nilai $\mathrm{P}=0,000$ bahwa terdapat pengaruh terapi aktifitas kelompok simulasi sensori tergadap penurunan depresi lanjut usia..

Menurut Stanley M (2002), Gangguan psikososial (kesepian dan depresi) merupakan masalah umum bagi sebagian besar penghuni panti werdha, terutama bagi mereka yang memiliki derajat imobilitas dan mereka yang hanya memiliki sedikit pengunjung dan tidak memiliki sistem pendukung yang lain. Reminiscence (terapi dengan mengingat masa lalu), memotivasi 
kembali, musik dan kelompok aktivitas yang lain dapat sangat membantu mengurangi gangguan psikososial (depresi dan kesepian). Gangguan psikososial merupakan ketidakmampuan seseorang dalam menghadapi perubahan-perubahan dalam hidupnya. Menurut kuntjoro (2002) pada umumnya setelah orang memasuki lanjut usia maka ia mengalami penurunan fungsi kognitif (proses belajar, persepsi, pemahaman, pengertian, perhatian) dan psikomotor ( meliputi hal-hal yang berhubungan dengan dorongan kehendak seperti gerakan, tindakan, koordinasi) sehingga menyebabkan reaksi dan perilaku lansia menjadi semakin lambat dan menjadi kurang cekatan. Terapi aktivitas kelompok stimulasi sensoris merangsang panca indera untuk mengekspresikan apa yang dirasakan oleh lansia sehingga meningkatkan fungsi kognitif dan psikomotor lansia yang menyebabkan reaksi dan perilaku lansia lebih aktif dan cekatan, dengan demikikian akan mengurangi gangguan psikososial lansia.

Berdasarkan hasil analisis pada tabel 4.4 terdapat perbedaan nilai $\mathrm{p}$ dari kelompok eksperimen dan kelompok kontrol, dimana pada kelompok eksperimen harga $p=0,000$ lebih kecil dari 0,05 dan pada kelompok kontrol $p=0,317$. hal ini menunjukkan bahwa ada pengaruh terapi aktivitas kelompok stimulasi sensoris terhadap gangguan pikososial pada kelompok intervensi. Sedangkan pada kelompok kontrol yang tidak diberikan terapi aktivitas kelompok stimulasi sensoris tidak berpeluang mengalami penurunan gangguan psikologis. Hal ini sesuai dengan teori bahwa biasanya 


\section{KESIMPULAN}

\section{DAFTAR PUSTAKA}

klien yang tidak mau mengungkapkan komunikasi verbal akan terstimulasi emosi dan perasaannya, serta menampilkan respons, pemberian terapi aktivitas kelompok stimulasi sensoris adalah agar klien mampu mengekpresikan perasaannya ( B A Keliat, 2015). Jadi, dengan mengekspresikan perasaan melalui terapi aktivitas kelompok stimulasi sensoris dapat mengurangi gangguan psikososial lanjut usia. Hal ini sejalan dengan penelitian Nurafifah (2012) bahwa terdapat penurunan tinggat depresi lanjut usia setelah diberikan tindakan terapi aktifitas kelompok simulasi sensori.

Hasil penelitian menunjukan bahwa terdapat pengaruh terapi aktivitas kelompok stimulasi sensoris terhadap gangguan psikososial lanjut usia

Alimul, A. 2007. Riset Keperawatan dan Teknik Penulisan IImiah. Salemba Medika. Jakarta.

Keliat, B A. 2015. Keperawatan Jiwa (Terapi Aktivitas Kelompok). Edisi 2. EGC. Jakarta.

Notoadmodjo, S. 2012. Konsep dan Penerapan Metodologi Penelitian Ilmu Keperawatan. Salemba Medika. Jakarta.

Nugroho, W. 2008. Keperawatan Gerontik Edisi 3. EGC. Jakarta.। Nursalam. 2003. Konsep Dan Penerapan Metodologi Penelitian IImu Keperawatan. Salemba Medika. Jakarta.

Stanley, M. 2006. Buku Ajar Keperawatan Gerontik Edisi 2. EGC. Jakarta

Stuart dan Laraia (2005). Principles And Practice Of Psichiatric Nursing. Mosby Company, USA

Suliswati, Dkk. 2015. Konsep Dasar Keperawatan Kesehatan Jiwa. EGC. Jakarta.

Yosep, I, 2007, Keperawatan Jiwa, Rethika Adhimata. Bandung 